Erratum

\title{
Erratum to "Evidence for the Use of Isoflurane as a Replacement for Chloral Hydrate Anesthesia in Experimental Stroke: An Ethical Issue"
}

\author{
Maud Pétrault,, ${ }^{1,2}$ Thavarak Ouk, ${ }^{1,2}$ Cédrick Lachaud, ${ }^{1,2}$ Michèle Bastide, ${ }^{1,3}$ \\ Vincent Bérézowski, ${ }^{1,4}$ Olivier Pétrault, ${ }^{1,4}$ and Régis Bordet ${ }^{1,2}$ \\ ${ }^{1}$ EA 1046-Département de Pharmacologie Médicale, Faculté de Médecine, CHU Lille, 1 Place de Verdun, 59045 Lille Cedex, France \\ ${ }^{2}$ UDSL, 59000 Lille, France \\ ${ }^{3}$ IUT A, Université de Lille 1, 59653 Villeneuve d’Ascq Cedex, France \\ ${ }^{4}$ Université d'Artois, 62307 Lens, France \\ Correspondence should be addressed to Maud Pétrault; maud.petrault@univ-lille2.fr \\ Received 7 July 2014; Accepted 21 July 2014; Published 28 August 2014 \\ Copyright (C) 2014 Maud Pétrault et al. This is an open access article distributed under the Creative Commons Attribution License, \\ which permits unrestricted use, distribution, and reproduction in any medium, provided the original work is properly cited.
}

The first and the last names of the authors were reversed in the published paper. The corrected names are as shown above. 


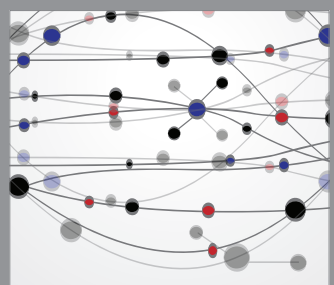

The Scientific World Journal
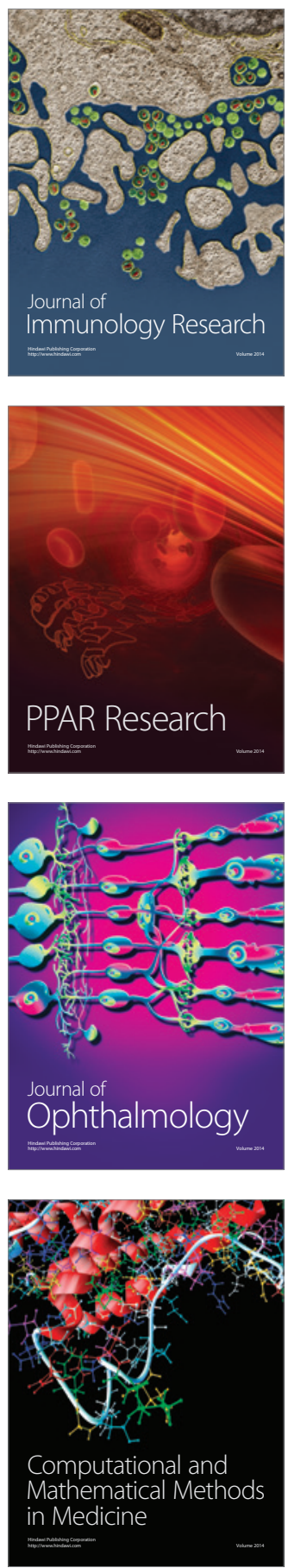

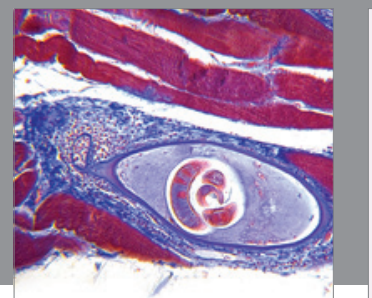

Gastroenterology

Research and Practice
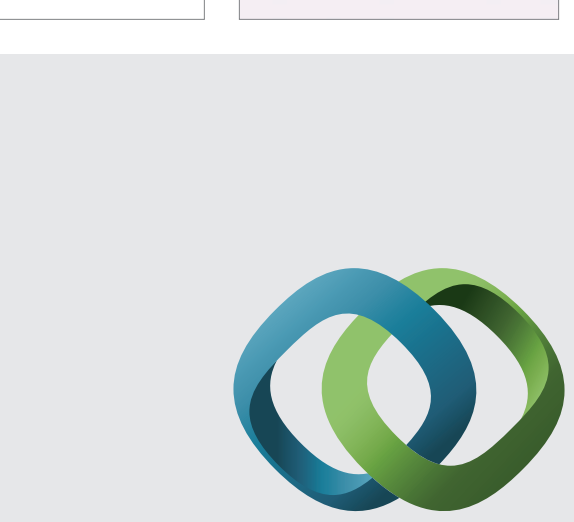

\section{Hindawi}

Submit your manuscripts at

http://www.hindawi.com
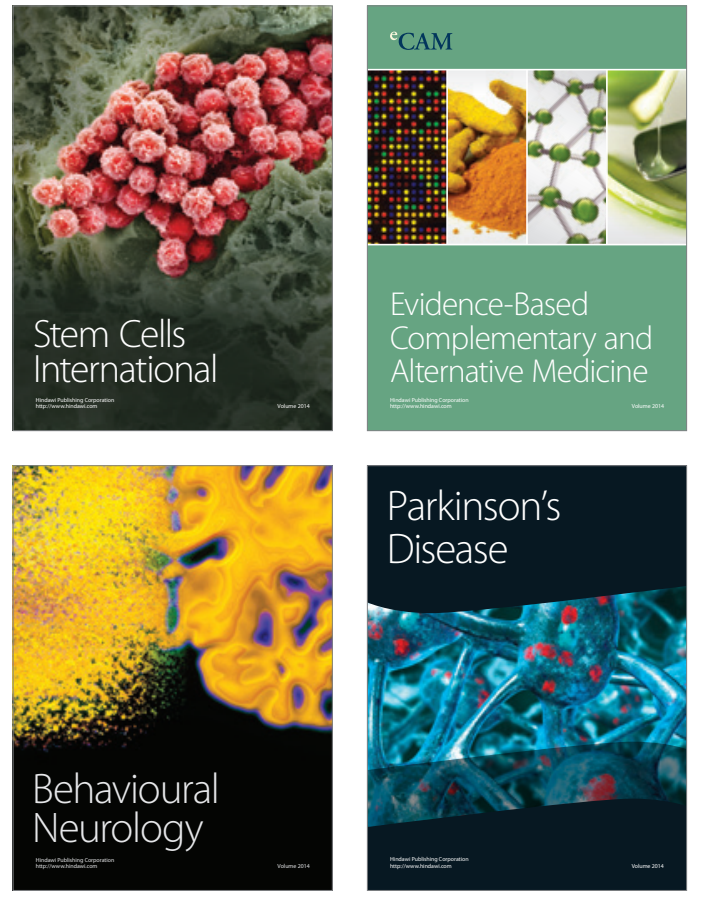
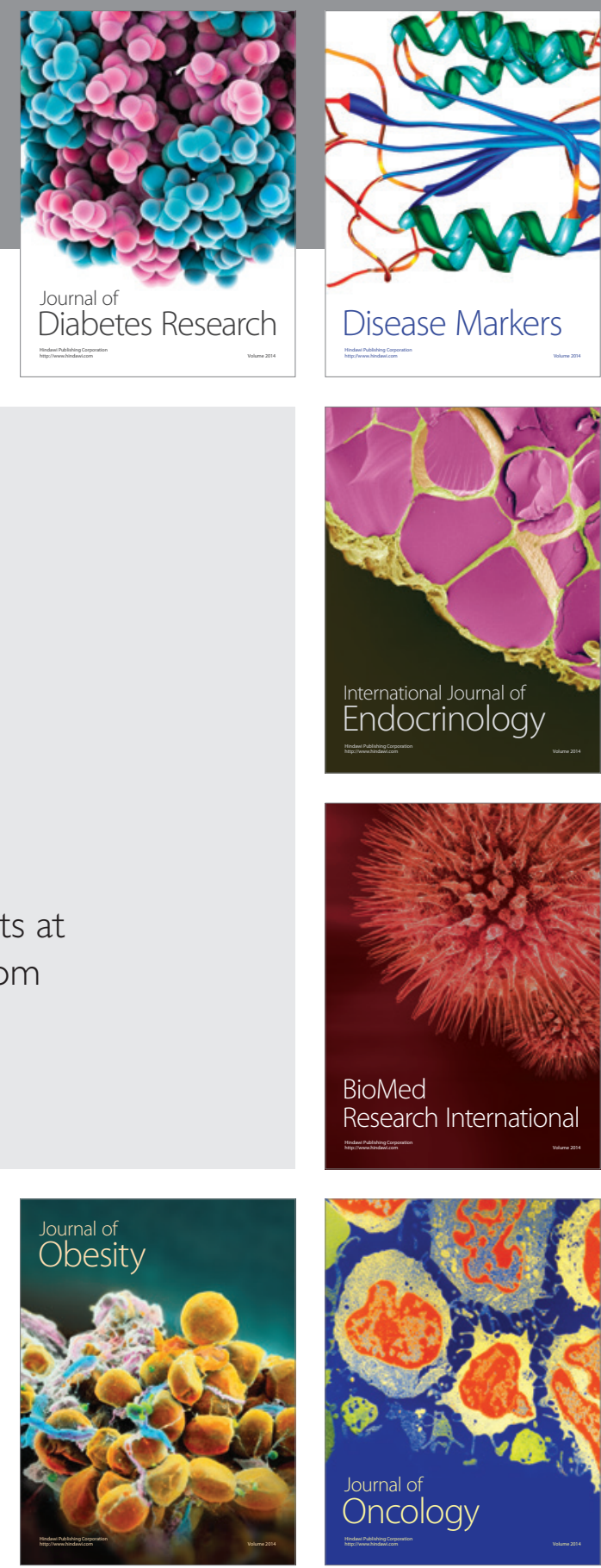

Disease Markers
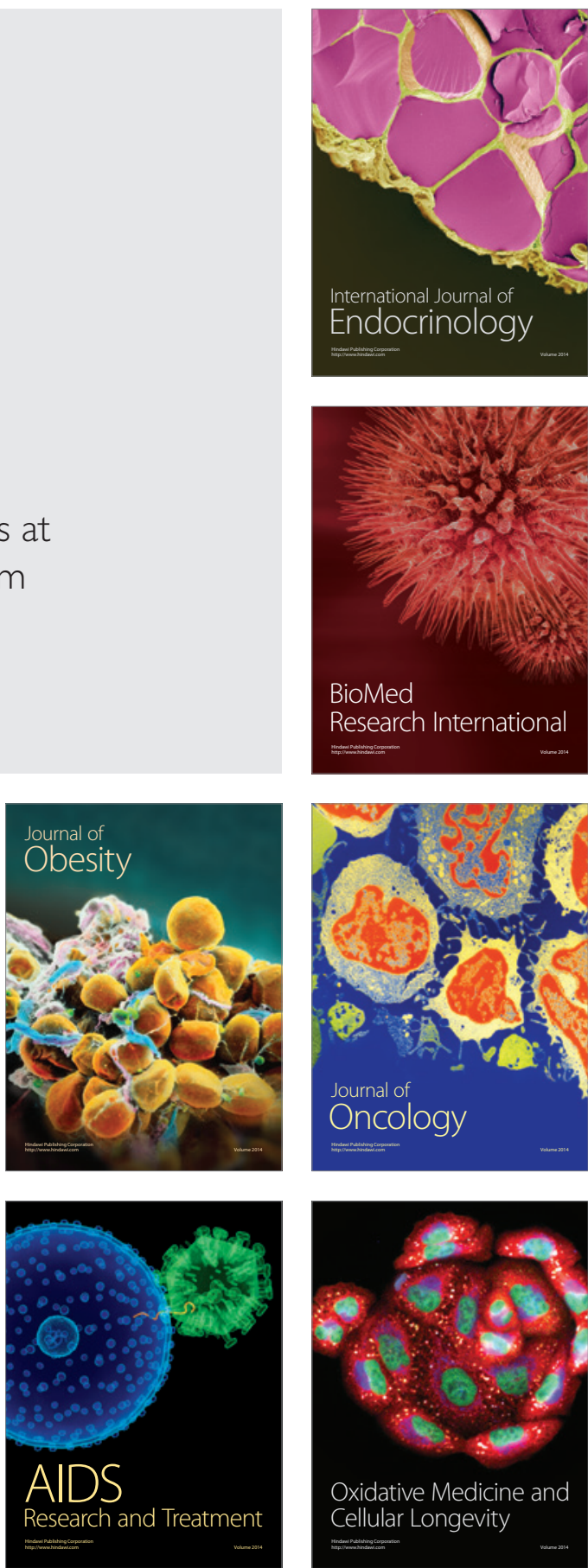